\title{
Fusion zone purification of metal containing oxide inclusions via laser welding
}

\author{
M. L. HU*, T. C. YANG, H. C. WU, C. CHEN ${ }^{\dagger}$ \\ Department of Materials Science and Engineering, National Taiwan University, 1 Roosevelt Road, Sector 4 \\ Taipei, Taiwan 106, Republic of China \\ E-mail:gchen@ntu.edu.tw
}

Slag and oxide inclusions are often observed in the alloy and more frequently in the welded structure. The influence of inclusions on mechanical properties, which is similar to that of porosity, is detrimental to performance. It was reported that oxide inclusions tend to affect fracture toughness and fatigue properties of the welds [1-3]. The presence of oxide inclusions often accounts for poor weld quality of repaired turbine blades in power plants [4]. Hence, the reduction of inclusions in metal is crucial for improved mechanical properties.

For deep-penetration laser welding, the power density is typically between $0.5 \times 10^{6}$ to $5 \times 10^{7} \mathrm{~W} / \mathrm{cm}^{2}$ [5]. With a keyhole being created, the temperature in the keyhole can be greater than the vaporization temperature of the elements in the material [6] and the weld pool temperature can be raised to about $2500{ }^{\circ} \mathrm{C}$ [7]. It is noted that there is a great difference in absorption coefficients between oxide and metal during laser welding. As a result, oxide inclusions are preferentially heated and vaporized out of the melt zone. The reduction of oxide inclusions in metals via laser welding, known as the fusion zone purification [8], can be useful in engineering applications.

The purpose of this study was to investigate the effectiveness of fusion zone purification with repeated laser welding. AISI 410 stainless steel (SS) sheet together with oxide and metal powders $\left(\mathrm{SiO}_{2}, \mathrm{ZrO}_{2}\right.$, and 410 $\mathrm{SS}$ ) were used to manufacture a small region of metaloxide composite within the test coupons. Microstructural observations and mechanical tests were conducted on welded specimens to characterize the extent of excluding oxides from the metal component after laser welding.

AISI $410 \mathrm{SS}$ sheet of $3.4 \mathrm{~mm}$ thickness was used as the base material to manufacture a region containing $\mathrm{SiO}_{2}$ and $\mathrm{ZrO}_{2}$ particles within the test coupons. The oxide powder was mixed with the $410 \mathrm{SS}$ powder to form the composite powder containing about $10 \mathrm{wt} \%$ of a given type of oxide. The nominal chemical composition of $410 \mathrm{SS}$ powder in weight percent was $0.15 \mathrm{C}$, $12.50 \mathrm{Cr}, 0.11 \mathrm{Ni}, 0.02 \mathrm{Mo}, 0.14 \mathrm{Mn}, 0.51 \mathrm{Si}, 0.02 \mathrm{~S}$, and balance Fe. A small amount of binder was also added in the composite powder prior to fill in the V-groove on the test coupon as shown in Fig. 1.The $410 \mathrm{SS}$ powder was then sprayed on top of the V-groove via a coaxial

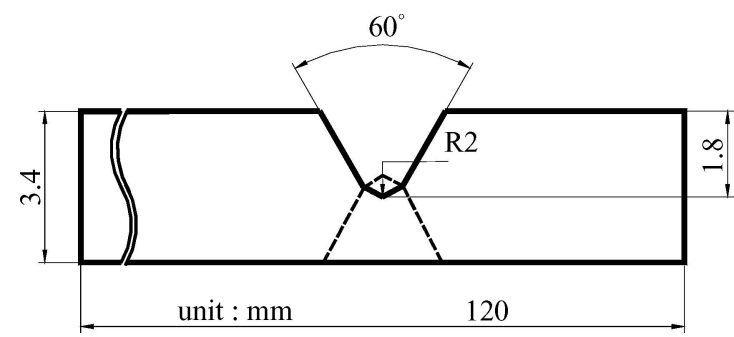

Figure 1 Schematic diagram showing the V-groove in the $410 \mathrm{SS}$ test coupon for manufacturing the metal-oxide composite region. Note that a second V-groove (dashed line) was introduced after filling out the first V-groove with consolidated metal-oxide composite.

powder feed nozzle. By proper adjustment of processing parameters $(3.0 \mathrm{~kW}$ laser power, $600 \mathrm{~mm} / \mathrm{min}$ travel speed, $30 \mathrm{~g} / \mathrm{min}$ powder flow rate, and a stand-off distance of $25 \mathrm{~mm}$ ), the sprayed $410 \mathrm{SS}$ powder mixed with the composite powder in the $\mathrm{V}$-groove to form fairly good joints. This method helped to reduce spattering of oxide particles in the process and kept them in the specimen. After spraying on one-side of the test coupon, a symmetrical groove was then made on the reverse side, repeating the steps just discussed.

Laser "keyhole" welding was performed on the oxide-impregnated region of test coupons using a Rofin-Sinar $8505 \mathrm{~kW} \mathrm{CO}$ laser. All specimens were processed with $3.2 \mathrm{~kW}$ laser power and a travel speed of $600 \mathrm{~mm} / \mathrm{min}$. Two full-penetration welding passes along the centerline of $\mathrm{V}$-grooves, one on each face, were executed on specimens to facilitate mechanical testing within the weld metal. The resulting weld metal had a fairly uniform width of approximately $3 \mathrm{~mm}$. Furthermore, laser-welded specimens with four passes, i.e. two passes on each face, were also conducted. All welded specimens were subsequently tempered at $650{ }^{\circ} \mathrm{C}$ for $2 \mathrm{hr}$; such welded and tempered specimens were designated as WT-2 and WT-4 specimens for weld passes of 2 and 4, respectively. Besides, $\mathrm{SiO}_{2}$ and $\mathrm{ZrO}_{2}$ are added after the number to indicate the type of oxides in specimens, e.g. WT-2-SiO 2 and WT-2- $\mathrm{ZrO}_{2}$ specimens.

Impact and fatigue crack growth tests were conducted on laser-welded specimens at room temperature. The subsize impact specimen ( $2.5 \mathrm{~mm}$ thick)

\footnotetext{
*Present address: Materials College, Huazhong University of Science and Technology, Wuhan 430074, Peoples' Republic of China.

†Author to whom all correspondence should be addressed.
} 

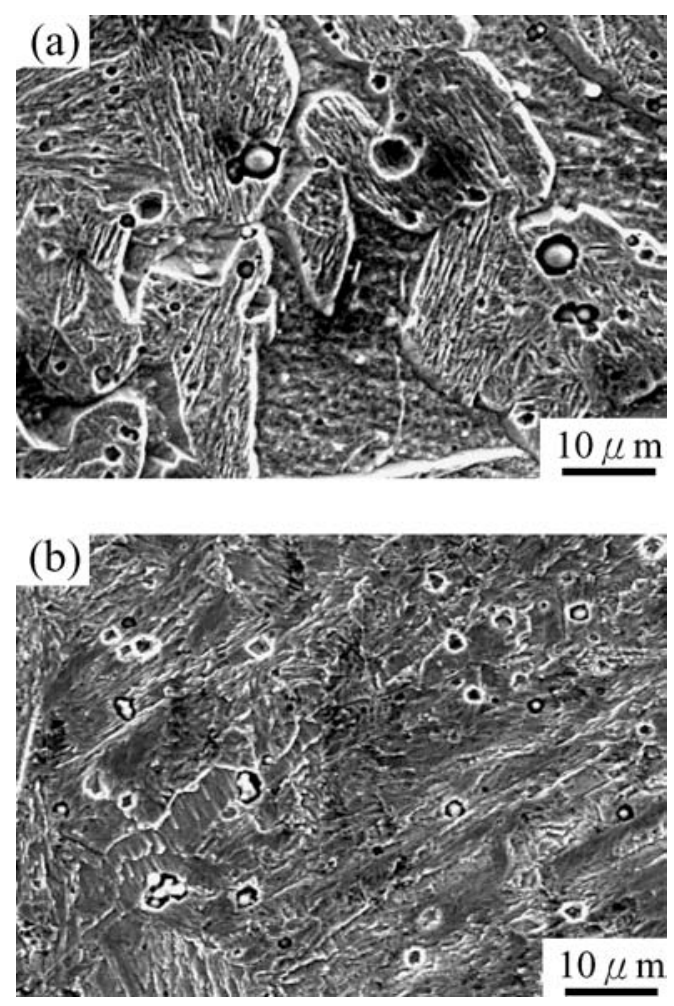

Figure 2 SEM photographs showing the metal (410 SS) and (a) $\mathrm{SiO}_{2}$ and (b) $\mathrm{ZrO}_{2}$ composite regions prior to purification experiments

was employed in the Charpy test and the impact result was the average of three specimens. The fatigue crack growth tests were performed on compacttension (CT) specimens with the crack growth direction along the centerline of the welds. The configuration of CT specimens was the same as in a previous study [9] and the experimental procedures met the ASTM E647-91 standard [10]. Additionally, fractographic examinations of impact-fractured specimens were examined by scanning electron microscopy (SEM).

Fig. 2 shows the resultant microstructures of the artificial region of metal-oxide composite prior to laser welding. It reveals a substantial number of oxide particles remaining in the matrix of $410 \mathrm{SS}$; however, the bonding between them is poor. The size of oxide particles is about $2-5 \mu \mathrm{m}$ in diameter, and the volume fraction of $\mathrm{SiO}_{2}$ and $\mathrm{ZrO}_{2}$ is approximately 11 and $6 \%$, respectively. Such test coupons that contained a metaloxide composite region were the bases for subsequent works.

Fig. 3 demonstrates that oxide inclusions in WT-4$\mathrm{SiO}_{2}$ specimens can be excluded significantly from the weld metal by laser welding. It consists of tempered martensite with no discernible oxide particles, resembling the laser-welded 410 SS (no oxide inclusions) after the same temper treatment. Similar observations were also found in WT-4- $\mathrm{ZrO}_{2}$ specimens. Nevertheless, the complete exclusion of oxide inclusions from the weld metal by laser welding remains very difficult. It should be noted that small oxide particles were hard to distinguish from SEM metallographs, however, they could be found easily within dimples of impactfractured specimens.
TABLE I Impact values of various laser-welded specimens

\begin{tabular}{llll}
\hline $\mathrm{WT}-2-\mathrm{SiO}_{2}$ & $\mathrm{WT}-2-\mathrm{ZrO}_{2}$ & $\mathrm{WT}-4-\mathrm{SiO}_{2}$ & $\mathrm{WT}-4-\mathrm{ZrO}_{2}$ \\
\hline $8.6 \mathrm{~J}$ & $8.8 \mathrm{~J}$ & $11.5 \mathrm{~J}$ & $11.6 \mathrm{~J}$ \\
\hline
\end{tabular}

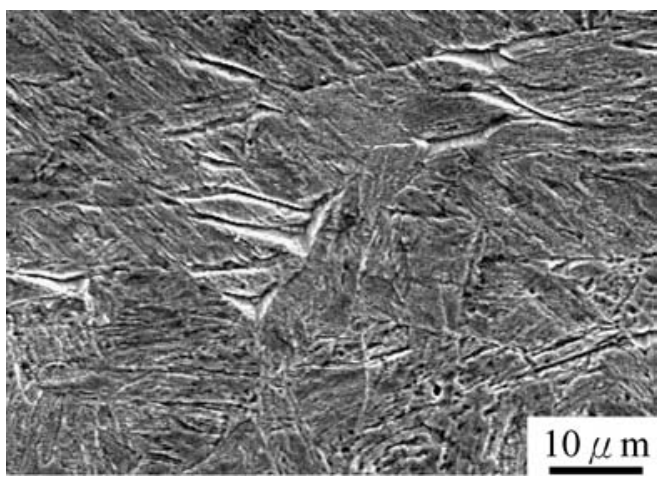

Figure 3 SEM photograph showing the microstructure of the weld metal in the WT-4-SiO 2 specimen.

Table I lists the impact results of WT-2- and WT4- $\left(\mathrm{SiO}_{2}\right.$ and $\left.\mathrm{ZrO}_{2}\right)$ specimens. The impact energy of laser-welded specimens was in the neighborhood of 9 $\mathrm{J}$ for WT-2 specimens and $12 \mathrm{~J}$ for WT-4 specimens. The increase in impact energy of specimens with more weld passes could be attributed to the removal of more oxide inclusions and the reduction of particle size in the matrix; the impact toughness of WT-4- $\left(\mathrm{SiO}_{2}\right.$ and $\left.\mathrm{ZrO}_{2}\right)$ specimens was only slightly less than that of the 410 SS weld metal $(\sim 12.7 \mathrm{~J})$ after tempering.

The size and distribution of oxide particles on the fracture surface of the weld metal after impact testing could be used to examine the effectiveness of fusion zone purification. Fig. 4 exhibits the impact-fractured surfaces of WT-2- and WT-4- $\left(\mathrm{SiO}_{2}\right.$ and $\left.\mathrm{ZrO}_{2}\right)$ specimens. Clearly, the latter contained less oxide particles than the former, showing that more weld passes better purify the fusion zone during laser welding. The size of dimples seemed to depend on the particle size of oxides as well. The oxide inclusions were smaller and more dispersed in WT-4 specimens than those in WT-2 specimens.

Fatigue crack growth tests were performed only on WT-4 specimens due to the fact that oxide inclusions in these specimens were greatly removed. Fig. 5 presents the fatigue crack growth rate, $\mathrm{d} a / \mathrm{d} N$, versus the stress intensity factor range $(\Delta K)$ curves for WT-4 specimens, in which the $\mathrm{d} a / \mathrm{d} N$ vs $\Delta \mathrm{K}$ of the $410 \mathrm{SS}$ weld metal is also presented. The fracture surface appearance, as well as fatigue crack growth rate characteristics, of WT-4- $\left(\mathrm{SiO}_{2}\right.$ and $\left.\mathrm{ZrO}_{2}\right)$ specimens were similar to those of the $410 \mathrm{SS}$ weld metal, indicating the effectiveness of oxide inclusions removal by multi-run laser welding.

In summary, a significant effect of fusion zone purification after laser "keyhole" welding was demonstrated. Oxide inclusions such as $\mathrm{SiO}_{2}$ and $\mathrm{ZrO}_{2}$ in the $410 \mathrm{SS}$ matrix could be reduced considerably by repeated laser welding. The impact energy of WT-2- and WT-4- $\left(\mathrm{SiO}_{2}\right.$ and $\mathrm{ZrO}_{2}$ ) specimens was about 9 and $12 \mathrm{~J}$, respectively. 

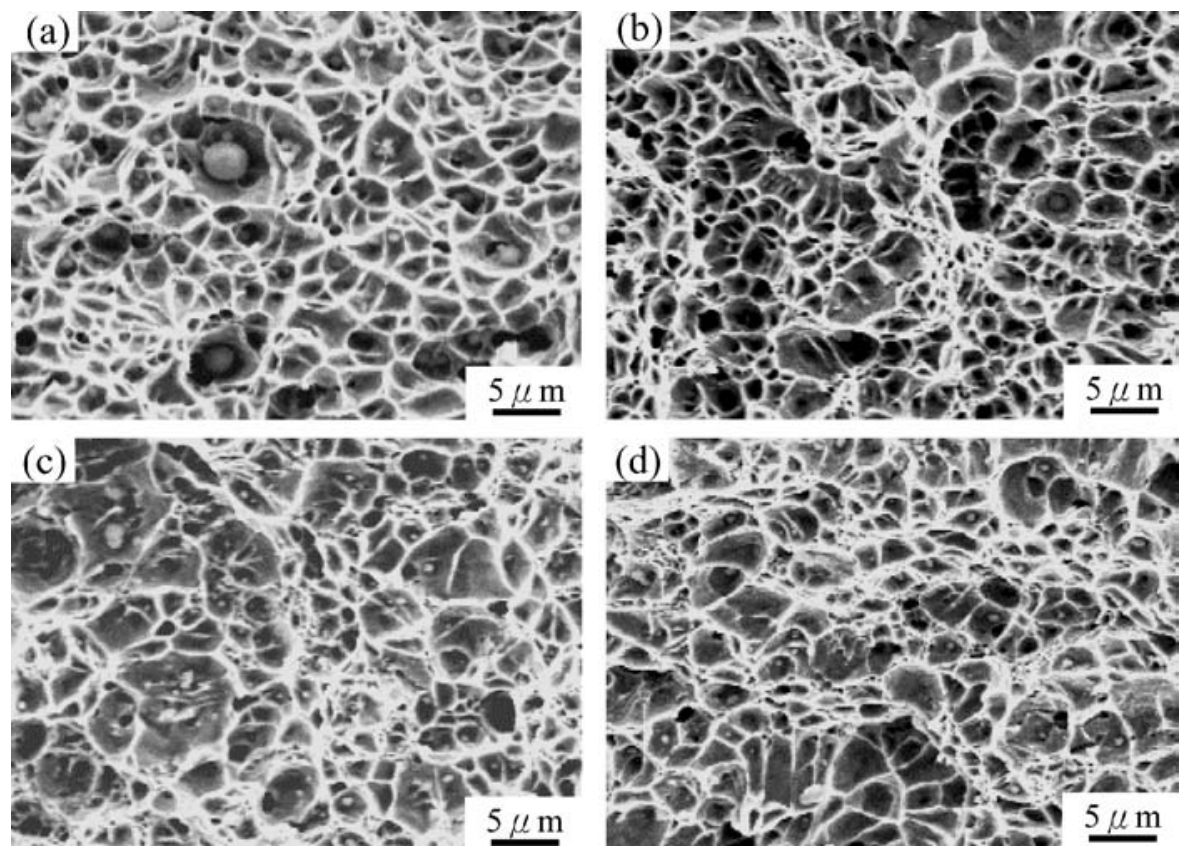

Figure 4 Impact-fractured surfaces of (a) WT-2-SiO 2 , (b) WT-4-SiO $\mathrm{W}_{2}$, (c) WT-2-ZrO $\mathrm{Wr}_{2}$, and (d) $\mathrm{WT}-4-\mathrm{ZrO}_{2}$ specimens.

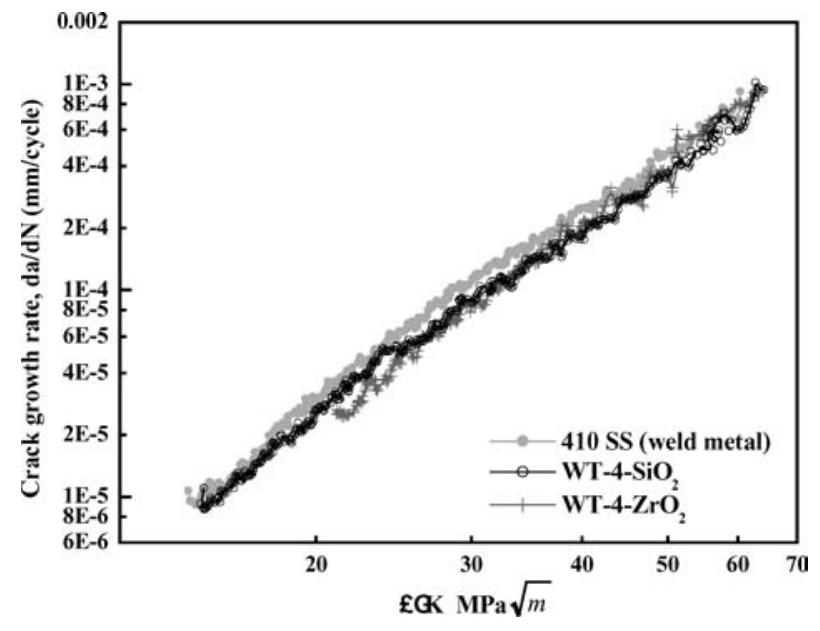

Figure 5 The $\mathrm{d} a / \mathrm{d} N$ versus $\Delta \mathrm{K}$ curves for WT-4-SiO 2 and WT-4-ZrO specimens.

The increase in impact energy of laser-welded specimens with more weld passes was attributed to the removal of more oxide inclusions and the reduction of particle size in the matrix. The fatigue crack growth rate characteristics of oxide-containing specimens were similar to those of the 410 SS weld metal after excluding oxide inclusions to a certain extent by multi-run laser welding.

\section{Acknowledgment}

The authors gratefully acknowledge the support of the Republic of China National Science Council (Contact No. NSC92-2216-E-002-007).

\section{References}

1. Y. MURAKAMI, M. TAKADA and T. TORIYAMA, Int. J. Fatigue 20 (1998) 661.

2. Y. MURA KAMI, T. NOMOTO and T. UEDA, Fatigue Fract. Eng. Mater. Struct. 22 (1999) 581.

3. A. RAY, S. K. PAUL and S. JHA, J. Mater. Eng. Perform. 4 (1995) 679.

4. V. VISWANATHAN, R. FRISCHMUTH and D. GANDY, Power Eng. 103 (1999) 20.

5. C. B ANAS, in “The Industrial Laser Annual Handbook," 1986 edited by D. Belforte and M. Levitt (PennWell Books, Tulsa, 1986) SPIE Vol. 629, p. 69.

6. E. A. METZB OWER, Metall. Trans. 24B (1993) 875.

7. D. A. SCHAUER, W. H. GIEDT and S. M. SHINTAKU, Weld. J. 57 (1978) 127.

8. E. M. BREINAN and C. M. BANAS, in "Advances in Metal Processing," edited by J. J. Burke, R. Mehrabian and V. Weiss (Plenum Press, New York, 1981) p. 111.

9. L. W. TSA Y, W. H. HUANG and C. CHEN, Fatigue Fract. Eng. Mater. Struct. 20 (1997) 1033.

10. Annual Book of ASTM Standards E647-91 (Philadelphia, 1991) Vol. 03. 01, p. 654.

Received 21 December 2004

and accepted 4 January 2005 